\title{
Survival, starvation, and activity in Heterorhabditis megidis (Nematoda: Heterorhabditidae)
}

\author{
Paul F.L. Fitters ${ }^{* 1}$, Christine T. Griffin \\ Institute of Bioengineering and Agroecology and Department of Biology, National University of Ireland, Maynooth, Co. Kildare, Ireland
}

Received 4 July 2005; accepted 18 August 2005

Available online 29 September 2005

\begin{abstract}
Infective juveniles (IJs) of entomopathogenic nematodes do not feed but have ample stored energy reserves and can survive for several months in soil or in water. Intraspecific variation in survival of Heterorhabditis megidis has been observed for eight isolates of $H$. megidis stored in water at $20^{\circ} \mathrm{C}$ for up to 14 weeks with the $50 \%$ survival time $\left(\mathrm{ST}_{50}\right)$ ranging from 5.6 to 12.5 weeks. How important physical and behavioral attributes were in explaining this variation in survival was explored using stepwise regression. Included in the analysis were: initial energy reserves (measured by image analysis densitometry), size (area and length) the time at which $50 \%$ of energy reserves were depleted $\left(\mathrm{ET}_{50}\right)$, and motility (head movements/min in week 0 ). Energy depletion rate, $\mathrm{ET}_{50}$, is an important predictor of survival, explaining $93.8 \%$ of the variation in $\mathrm{ST}_{50}$ among isolates. Energy depletion rate was highest in the first week, a time at which $H$. megidis $\mathrm{IJ}_{\mathrm{S}}$ were spontaneously active during storage. By week 5, when IJs had begun to die, some individuals had completely depleted their energy reserves, supporting the hypothesis that death was a result of starvation. In a second stepwise regression, performed to explore what factors contribute to variation in rate of energy depletion, motility accounted for $60.1 \%$ of the variation in $\mathrm{ET}_{50}$. With the inclusion of initial energy reserves, length, and area, $88.5 \%$ of the variation was accounted for. We conclude that intraspecific variation in survival of $H$. megidis in water is due largely to variation in rates of depletion of energy reserves, which in turn is strongly associated with levels of locomotory activity.
\end{abstract}

(C) 2005 Elsevier Inc. All rights reserved.

Keywords: Energy reserves; Biocontrol; Entomopathogenic nematodes; Behavior; Persistence; Longevity

\section{Introduction}

Entomopathogenic nematodes (EPN) of the families Heterorhabditidae and Steinernematidae are used for the biological control of a number of insect pests (Gaugler, 2002; Grewal et al., 2005). Although more than 40 species of EPN have been described, only a few have been commercialized. Amongst these is Heterorhabditis megidis Poinar, Jackson, and Klein, which occurs naturally in temperate regions of Europe, North America, and Japan (Hominick, 2002) and is particularly effective against black vine weevil

\footnotetext{
* Corresponding author. Fax: +353 18040212.

E-mail address: pfitters@botanic.teagasc.ie (P.F.L. Fitters).

${ }^{1}$ Present address: Teagasc, College of Amenity Horticulture, Botanic Gardens, Glasnevin, Dublin 9, Ireland.
}

(Otiorhynchus sulcatus, Fabricius) (Long et al., 2000; Fitters et al., 2001). Most of the life cycle of EPN take place within the host. There is one soil-dwelling stage, the third stage infective juvenile (IJ), which is a non-feeding stage that emerges from the depleted insect cadaver in search of new hosts.

It has been demonstrated for various species of plant and animal parasitic nematodes that longevity of the infective stage is dependent on availability of reserves (Croll and Mathews, 1973; Van Gundy et al., 1967). The assumption that IJs die of starvation has rarely been explicitly tested for any species of EPN. Qiu and Bedding (2000) showed that survival rate and depletion of reserves of Steinernema carpocapsae (Weiser) were both affected in a similar way by different storage conditions. They concluded that IJ lifespan is largely dependent on the rate of energy 
consumption, which in turn was influenced by various factors, including activity. IJs survived significantly longer in shallow tap water than on a shaker, and Qiu and Bedding (2000) suggest that this is because the IJs in shallow water became inactive and so conserved reserves.

The period IJs survive in storage (shelf life), either in water or a commercial formulation, is an important factor limiting the use of EPNs as a biological pesticide (Grewal and Georgis, 1998). Under laboratory conditions, IJs are frequently stored in shallow water at a concentration of no more than 20,000 IJs/ml (Woodring and Kaya, 1988). Stored this way at $4-10^{\circ} \mathrm{C}$, Steinernema spp. can be kept for 6 to 12 months without much loss of activity, whereas Heterorhabditis spp. normally do not store well beyond 4 months (Woodring and Kaya, 1988). At higher temperatures, survival time is reduced (Molyneux, 1985; Strauch et al., 2000). Energy reserves - particularly neutral lipids are an important indicator of quality (infectivity and motility) of stored nematodes. Lipids, carbohydrate (especially glycogen), and protein, accumulated during the preceding juvenile stages within the host, all provide energy for IJs during storage (Lewis et al., 1995; Qiu and Bedding, 2000; Selvan et al., 1993b). Lipid is the main energy reserve, constituting between 32 and $49 \%$ of IJ body weight (Fitters et al., 1999; Lewis et al., 1995; Menti et al., 2003; Selvan et al., 1993b). In most species of EPN, activity and infectivity decline as lipids are depleted (Lewis et al., 1995; Patel et al., 1997). An exception is $S$. carpocapsae, for which glycogen was shown to be important in maintaining infectivity in aged IJs (Patel and Wright, 1997; Wright et al., 1997). Elucidation of which factors are important determinants of survival should facilitate improvements in shelf life through genetic or technological manipulations.

We pose the question: is life span of $H$. megidis IJs controlled by the rate of energy expenditure? We explore this using IJs of eight isolates stored in shallow tap water at $20^{\circ} \mathrm{C}$. If starvation is the main cause of mortality, then differences in survival between isolates should reflect different starting levels of energy reserves, and/or differences in the rate at which the reserves are utilized. We also ask to what extent differences in initial reserves, size or activity of IJs explain the rate at which reserves are depleted.

\section{Materials and methods}

\subsection{Nematode cultures}

The experiment was run three times using different nematode culture batches for each experimental run. In each run the same eight $H$. megidis isolates from diverse locations of North West Europe were used (Table 1). Nematodes were reared in larvae of the greater wax moth, Galleria mellonella (L.) (The Mealworm Company, Sheffield, UK). In each experimental run the emerging IJs were pooled for each isolate and washed three times by sedimentation in tap water. Washed IJs were stored (about $1000 \mathrm{IJs} / \mathrm{ml}$ ) at $9^{\circ} \mathrm{C}$ for up to 5 days. Aliquots of IJ suspen-
Table 1

Origin and source of the North West European Heterorhabditis megidis isolates used

\begin{tabular}{|c|c|c|}
\hline Isolate & Origin & Source \\
\hline U17 & Tallinn, Estonia & $\begin{array}{l}\text { C.T Griffin and M.J. Downes, NUI, } \\
\text { Maynooth, Ireland }\end{array}$ \\
\hline EU80 & Tsitre, Estonia & $\begin{array}{l}\text { C.T. Griffin and M.J. Downes, NUI, } \\
\text { Maynooth, Ireland }\end{array}$ \\
\hline UK211 & Dorset, England & W.M. Hominick, CABI, UK \\
\hline $\mathrm{HSH}$ & Kiel, Ge & R.U. Ehlers, Kiel University, Germany \\
\hline HW7 & $\begin{array}{l}\text { Wageningen, } \\
\text { The Netherlands }\end{array}$ & $\begin{array}{l}\text { P.R. Westerman, Van Hall Institute, } \\
\text { The Netherlands }\end{array}$ \\
\hline HF85 & $\begin{array}{l}\text { Flevopolder, } \\
\text { The Netherlands }\end{array}$ & $\begin{array}{l}\text { P.R. Westerman, Van Hall Institute, } \\
\text { The Netherlands }\end{array}$ \\
\hline EU $85 / 2$ & Mordrup, Denmark & $\begin{array}{l}\text { C.T. Griffin and M.J. Downes, NUI, } \\
\text { Maynooth, Ireland }\end{array}$ \\
\hline HSIE & Siedlce, Poland & R.U. Ehlers, Kiel University, Germany \\
\hline
\end{tabular}

sion were than transferred to $5 \mathrm{~cm}$ diam. petri dishes at a concentration of $500 \mathrm{IJs} / \mathrm{ml}(10 \mathrm{ml} / \mathrm{dish})$. Lidded dishes were wrapped with laboratory sealing film (Parafilm) and stored at $20^{\circ} \mathrm{C}$ for up to 14 weeks in the dark. In each run there were eight dishes of each isolate; each dish was assessed once only. Survival and energy reserves were measured after 0 ( 1 day storage), 1, 2, 3, 5, 7, 10, and 14 weeks. Motility was recorded in week 0 .

\subsection{Survival, energy reserves, and size}

Living IJs were separated from dead ones by overnight passage through a $35 \mu \mathrm{m}$ sieve, and the number of live IJs was assessed from six replicate counts of $50 \mu 1$.

Energy reserves can be assessed in various ways, including chemical extraction and analysis of components, and in situ staining of neutral lipids with Oil Red O (e.g., Patel et al., 1997). Image analysis densitometry of unstained IJs can be used to assess the energy reserves of EPN (Fitters et al., 1997; Qiu and Bedding, 1999). Amongst the advantages of this method are that it provides data for individual nematodes and can be used even when numbers of surviving nematodes are very low.

Energy reserves of IJs were estimated by image analysis densitometry as described by Fitters et al. (1997). Fitters et al. (1997) showed that optical density (OD; the sum of the density or gray level of each pixel constituting the nematode image) is correlated with triacylglycerides, the main neutral lipid in nematodes. They also showed that OD/unit area (or OD $/ \mu \mathrm{m}^{2}$; mean gray level) was correlated with neutral lipids assessed on an 8-point scale as described by Patel et al. (1997). Length was measured using a binary thinning operation on the IJ image (Fitters et al., 1997). Prior to measuring, IJs were heat killed in water at approx. $80^{\circ} \mathrm{C}$. Measurements were performed on 30-40 randomly chosen IJs.

Motility was measured as head movements/min during normal sinusoidal movement ("waving"). A sweep of the anterior of the IJ to one side followed by return to the center was counted as one head movement. IJs in tap water 
wereobserved using a dissecting microscope illuminated with natural daylight. Room temperature was $20( \pm 1)^{\circ} \mathrm{C}$. IJs were left in situ for $1 \mathrm{~h}$ to acclimatize before motility was recorded. Motility was recorded for 30 randomly chosen IJs for 30 s/IJ.

\subsection{Statistics}

At each assessment period, data were analyzed using ANOVA followed by an all pairwise multiple comparison procedure (Tukey's or Student-Newman-Keuls (SNK), $P<0.05)$. Routine statistical analysis was performed using Sigma Stat for Windows 1.0 (Jandel Scientific, Erkath, Germany). Probit analysis (SPSS for Windows, Release 6.0) was used to calculate $50 \%$ survival time $\left(\mathrm{ST}_{50}\right.$; time at which $50 \%$ of the IJ survived) and 50\% energy depletion time $\left(\mathrm{ET}_{50}\right.$; time at which the IJ population had used up $50 \%$ of its energy reserves; see Section 3 for more details). Association between factors was explored using Pearson product-moment correlation $(P<0.05)$. Stepwise regression, used to identify the usefulness of predictors $(\alpha$-toremove: 0.15), was performed using Minitab for Windows, Release 12.1, 1998.

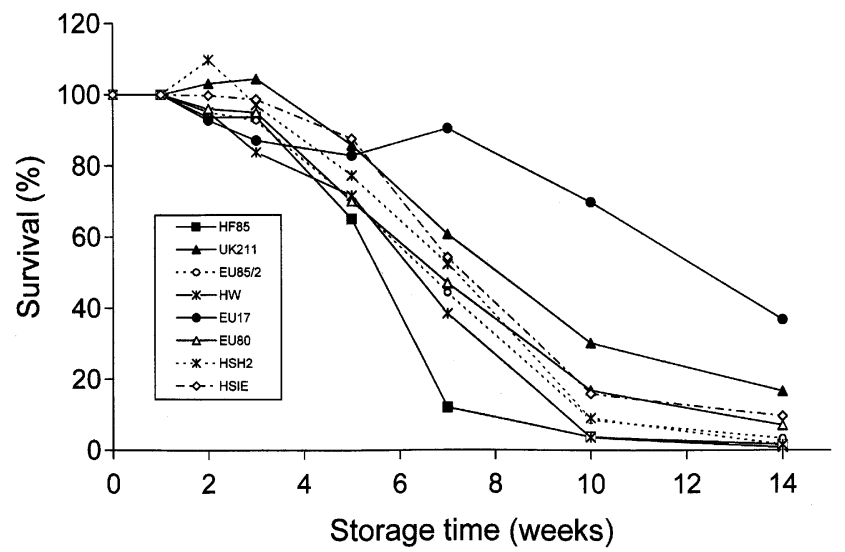

Fig. 1. Survival of eight Heterorhabditis megidis isolates stored in water at $20^{\circ} \mathrm{C}$. Each point represents the mean of three experiments. Error bars not shown; average $\mathrm{SE}=6.6$.

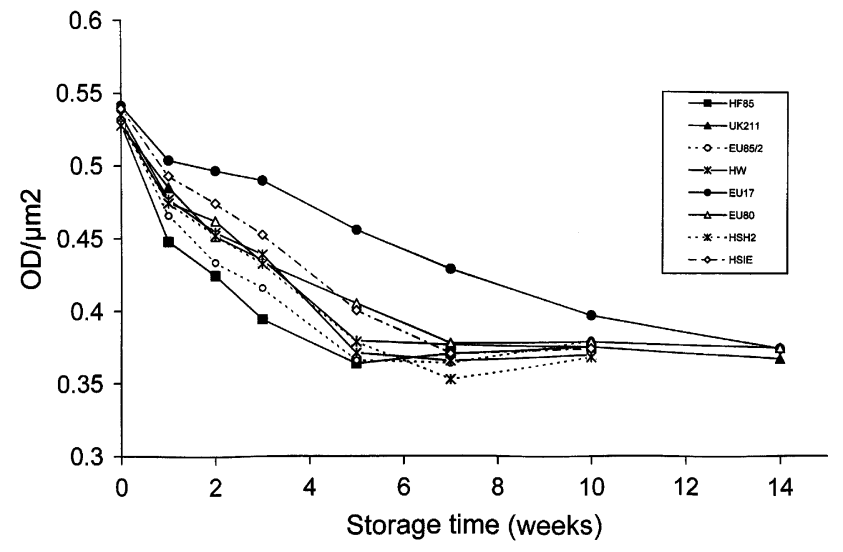

Fig. 2. Optical density per unit area $\left(\mathrm{OD} / \mu \mathrm{m}^{2}\right)$ of eight Heterorhabditis megidis isolates stored in water at $20^{\circ} \mathrm{C}$. Each point represents the mean of three experiments. Error bars not shown; average $\mathrm{SE}=0.007$.

\section{Results}

Survival of IJs in water at $20^{\circ} \mathrm{C}$ showed a typical sigmoid curve for all but one isolate (Fig. 1). IJs survived for up to 14 weeks. For most isolates the proportion alive had dropped below $80 \%$ in week 5 , and was below $30 \%$ in week 10. EU17 survived at a higher rate than the other isolates: 90 and $70 \%$ of IJs of this isolate were alive in weeks 5 and 10 , respectively. The $50 \%$ survival time $\left(\mathrm{ST}_{50}\right)$ of the eight isolates ranged from 5.6 to 12.5 weeks (Table 2). The $\mathrm{ST}_{50}$ of EU17 was significantly higher $(P<0.01)$ than that of all other isolates, based on the non-overlap of $95 \%$ fiducial limits.

There were differences $(F=3.52, \mathrm{df}=7,16, P<0.013)$ among the eight isolates in initial energy reserves measured as OD in week 0. HF85 had the lowest, and EU17 and HW79 had the highest OD values (Table 2).

To compensate for size differences among isolates, $\mathrm{OD} /$ $\mu \mathrm{m}^{2}$ was used to track changes in the level of reserves (Fig. 2). There was no difference $(P<0.05)$ among the eight isolates at week 0 , with an average of $0.53-0.54 \mathrm{OD} / \mu^{2}$. From week 1 on, EU17 always had the highest $\mathrm{OD} / \mu \mathrm{m}^{2}$, and it differed significantly $(F=11.2, \mathrm{df}=7,16, P<0.001)$

Table 2

Fifty percent survival time ( $\mathrm{ST}_{50}$ ) (with 95\% fiducial limits), 50\% energy depletion time ( $\left.\mathrm{ET}_{50}\right)$ (with $95 \%$ fiducial limits), motility ( $\pm \mathrm{SE}$ ) (head movements/ min.), initial energy reserves $( \pm \mathrm{SE})$, length $( \pm \mathrm{SE})$, and area $( \pm \mathrm{SE})$ of eight Heterorhabditis megidis isolates stored in water at $20^{\circ} \mathrm{C}$

\begin{tabular}{|c|c|c|c|c|c|c|}
\hline Isolate & $\mathrm{ST}_{50}$ (weeks) & $\mathrm{ET}_{50}$ (weeks) & Motility $^{\mathrm{a}}$ (movements/min) & Initial reserves ${ }^{\mathrm{a}}\left(\mathrm{OD}\right.$ units $\left.\times 10^{3}\right)$ & Length $^{\mathrm{b}}(\mu \mathrm{m})$ & $\operatorname{Area}^{\mathrm{a}}\left(\times 10^{4} \mu \mathrm{m}^{2}\right)$ \\
\hline EU17 & $12.5(11.0-14.7)$ & $5.6(4.9-6.3)$ & $13.4 \pm 1.4$ & $12.6 \pm 0.2 \mathrm{a}^{\mathrm{c}}$ & $837 \pm 6.7 \mathrm{a}^{\mathrm{c}}$ & $2.33 \pm 0.06 \mathrm{a}^{\mathrm{c}}$ \\
\hline UK211 & $8.5(7.4-9.9)$ & $2.8(1.1-4.2)$ & $14.1 \pm 1.6$ & $11.7 \pm 0.4 \mathrm{ab}$ & $836 \pm 6.8 \mathrm{~b}$ & $2.21 \pm 0.04 \mathrm{ab}$ \\
\hline HSH2 & $7.0(6.5-7.7)$ & $2.3(0.8-3.5)$ & $16.6 \pm 2.0$ & $11.9 \pm 0.5 \mathrm{ab}$ & $827 \pm 4.6 \mathrm{bc}$ & $2.25 \pm 0.05 \mathrm{a}$ \\
\hline EU85/2 & $6.7(6.1-7.3)$ & $2.1(0.4-3.5)$ & $18.1 \pm 1.8$ & $11.4 \pm 0.1 \mathrm{ab}$ & $825 \pm 3.9 \mathrm{de}$ & $2.13 \pm 0.01 \mathrm{ab}$ \\
\hline HSIE & $7.9(7.2-8.6)$ & $3.3(1.8-4.7)$ & $17.0 \pm 1.5$ & $12.0 \pm 0.2 \mathrm{ab}$ & $812 \pm 6.4 \mathrm{de}$ & $2.23 \pm 0.03 \mathrm{ab}$ \\
\hline EU80 & $7.2(6.5-8.0)$ & $2.7(2.0-3.3)$ & $17.3 \pm 1.6$ & $11.5 \pm 0.2 \mathrm{ab}$ & $806 \pm 4.5 \mathrm{e}$ & $2.16 \pm 0.01 \mathrm{ab}$ \\
\hline
\end{tabular}

All values are mean of three experiments.

${ }^{\text {a }}$ Measured in week 0 .

b Measured in week 3 .

${ }^{c}$ Within columns, the same or no letter indicates no significant differences between isolates; ANOVA, Student Newman-Keuls, $P>0.05$. 
from all other isolates at week 5 . With increased storage time, average $\mathrm{OD} / \mu \mathrm{m}^{2}$ tended towards an asymptotic minimum of $0.36 \mathrm{OD} \mathrm{U} / \mu^{2}$. The reduction in $\mathrm{OD} / \mu \mathrm{m}^{2}$ from the starting value (week 0 ) to the asymptotic minimum, averaging $0.18 \mathrm{U} / \mu^{2}$, represents available energy reserves. The time at which the IJ population had used up $50 \%$ of its available energy reserves $\left(\mathrm{ET}_{50}\right)$ ranged from 1.5 (HF85) to 5.6 (EU17) weeks (Table 2). EU17 had a significantly higher $\mathrm{ET}_{50}$ than all other isolates based on non-overlap of $95 \%$ fiducial limits.

The frequency distribution of energy reserves in the IJ population is shown for three isolates, EU17, UK211, and HF85 at weeks 0,2 , and 5 (Fig. 3). The $\mathrm{OD} / \mu \mathrm{m}^{2}$ of individual IJs ranged from 0.30 to $0.60 \mathrm{OD} \mathrm{U} / \mu \mathrm{m}^{2}$. UK211 and HF85 both started out with a normal distribution of $\mathrm{OD} / \mu \mathrm{m}^{2}$ in week 0 (Kolmogorov-Smirnov test), but the distribution was no longer normal by week 5 . At this time, the distribution of both HF85 and UK211 showed a tail of darker (high OD values) IJs (positively skewed). The majority of IJs (64\% of UK211 and $90 \%$ of HF85) had reached $0.36 \mathrm{OD} \mathrm{U} / \mu \mathrm{m}^{2}$ or less, but a small proportion remained quite dark at 0.46 $0.48 \mathrm{OD} \mathrm{U} / \mu^{2}{ }^{2}$. In contrast, only a few IJs of EU17 had reached $0.36 \mathrm{OD} \mathrm{U} / \mu \mathrm{m}^{2}$ by week 5 , representing a tail of more transparent IJs (low OD values) from the majority of dark nematodes (negatively skewed) (Fig. 3).

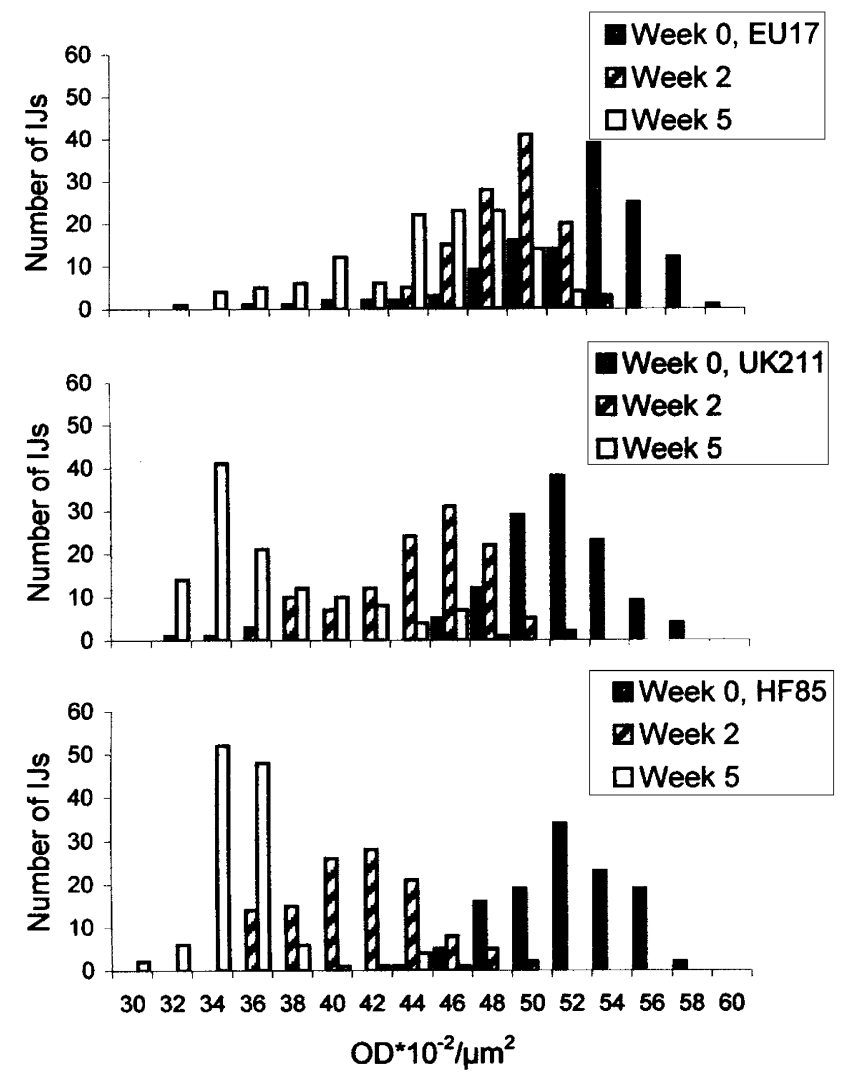

Fig. 3. Frequency distribution for optical density per unit area $\left(\mathrm{OD} / \mu \mathrm{m}^{2}\right)$ of individual IJs of three Heterorhabditis megidis isolates (EU17, UK211, and HF85) after 0,2 , and 5 weeks storage at $20^{\circ} \mathrm{C} . n=118-121$ for each isolate, data for three experiments combined.
There was a significant difference among isolates in both area $(F=5.0, \mathrm{df}=7,16, P<0.005)$ and length $(F=13.2$, $\mathrm{df}=7,16, P<0.001)($ Table 2). EU17 was longer than all other isolates. HF85 was the smallest nematode, differing significantly in area and length from EU17, HSH2, and HW79. The mean area of each of the eight isolates was greater at week 0 than at week 7 (data not shown). Overall, using data for all isolates, there was a significant (paired $t$ test, $n=8, t=6.13, P<0.001)$ decrease in area of $6.5 \%$ over a 7 -week storage period.

There was no significant difference among the eight isolates in motility, which ranged from an average of 13.4-18.3 head movements/min (Table 2).

The correlation between variables for the eight isolates is shown in Table 3. There was a strong correlation between $50 \%$ survival time $\left(\mathrm{ST}_{50}\right)$ and $50 \%$ energy depletion time $\left(\mathrm{ET}_{50}\right) \quad(r=0.97 ; \quad P<0.001)$; isolates that used up their reserves faster did not survive as long as those that utilized them at a slower rate. Stepwise regression analysis was performed to assess which factors had the largest influence on survival (Table 4). $\mathrm{ET}_{50}$ explained $93.8 \%$ of the variation in $\mathrm{ST}_{50}$. All factors together $\left(\mathrm{ET}_{50}\right.$, motility, total energy reserves, length, and area) explained $99.7 \%$ of $\mathrm{ST}_{50}$.

Significant $(P<0.05)$ negative correlation was found between motility and both $\mathrm{ST}_{50}(r=-0.85)$ and $\mathrm{ET}_{50}$ $(r=-0.78)$. Initial energy reserves were significantly correlated with $\mathrm{ET}_{50}(r=0.75)$. Neither area nor length was significantly correlated with either $\mathrm{ST}_{50}$ or $\mathrm{ET}_{50}$.

Stepwise regression analysis was again performed to assess which factors had the largest influence on depletion of energy reserves; $\mathrm{ST}_{50}$ was excluded from this analysis. Motility explained $60.1 \%$ of the variation in $\mathrm{ET}_{50}$, while initial energy reserves, area, and length added an additional $18 \%$ to the explanation (Table 4 ).

\section{Discussion}

Strong correlation $(r=0.96)$ was found between $50 \%$ energy depletion time and $50 \%$ survival time in $H$. megidis. By the time they die, IJs have become transparent, indicating loss of virtually all their lipid reserves. In week 5 , by which time IJs were dying, some individuals were recorded with $\mathrm{OD} / \mu \mathrm{m}^{2}$ levels of $0.30-0.32 \mathrm{OD} / \mu \mathrm{m}^{2}$. This corresponds to 1 on an 8-point neutral lipid index (Fitters et al., 1997), the value that is assigned to nematodes whose lipids are depleted (Patel et al., 1997). The presence of these lipiddepleted individuals is further evidence that IJs stored in tap water die of starvation. Varying storage condition (rather than isolate) to cause changes in lipid reserves in $S$. carpocapsae, Qiu and Bedding (2000) found that where reserves were depleted faster, these IJs also died sooner. For $H$. megidis, energy depletion rate explained $94 \%$ of the variation in 50\% survival time and by including the other factors (activity, initial reserves, and size) we could account for $99.7 \%$ of the variation in survival time.

Isolates from different geographical locations died at different rates. The Estonian isolate, EU17 stands out in 
Table 3

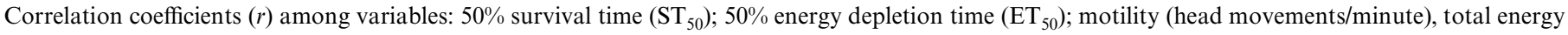
reserves (OD at week 0), length, and area of eight Heterorhabditis megidis isolates stored in water at $20^{\circ} \mathrm{C}$

\begin{tabular}{|c|c|c|c|c|c|}
\hline Variable & $\mathrm{ST}_{50}$ & $\mathrm{ET}_{50}$ & Motility & Initial reserves & Length \\
\hline \multicolumn{6}{|c|}{ Correlation coefficient $r(P)$} \\
\hline $\mathrm{ET}_{50}$ & $0.97(0.001)$ & & & & \\
\hline Motility & $-0.85(0.01)$ & $-0.78(0.02)$ & & & \\
\hline Total reserves & $0.65(0.80)$ & $0.75(0.03)$ & $-0.68(0.07)$ & & \\
\hline Length & $0.59(0.13)$ & $0.51(0.20)$ & $-0.77(0.03)$ & $0.69(0.06)$ & \\
\hline Area & $0.61(0.11)$ & $0.69(0.06)$ & $-0.70(0.05)$ & $0.99(0.001)$ & $0.74(0.04)$ \\
\hline
\end{tabular}

$P$ values are given in parenthesis. Significant correlations are in bold.

Table 4

Stepwise regression $\left(r^{2}\right.$ values) for the prediction of $50 \%$ survival time $\left(\mathrm{ST}_{50}\right)$ and $50 \%$ energy depletion time $\left(\mathrm{ET}_{50}\right)$

\begin{tabular}{|c|c|c|c|c|c|}
\hline & $\mathrm{ET}_{50}$ & Motility (movements/min) & Initial reserves (OD week 0) & Length & Area \\
\hline \multicolumn{6}{|l|}{$r^{2}$ for predictor } \\
\hline $\mathrm{ST}_{50}(P=0.01)$ & 93.8 & 96.4 & 98.7 & 99.5 & 99.7 \\
\hline $\mathrm{ET}_{50}(P=0.03)$ & - & 60.1 & 69.5 & 87.6 & 88.5 \\
\hline
\end{tabular}

Variables were added progressively to the regression until no further improvement was reached, with $\alpha=0.15$.

surviving longer and utilizing its reserves at a much slower rate than all other isolates. This exceptional position of EU17 was not maintained in another study (Fitters and Griffin, 2004), which included three of the eight isolates used here. In that study, EU17 did not differ from UK211 in these parameters though both of these isolates maintained their superiority over HF85. Simple batch variation is unlikely to be the cause of the difference in EU17, as both studies employed three separate culture batches of each isolate. Fitters and Griffin's research was conducted 2 years later than the present; continuous laboratory sub-culturing may have genetically altered the population (Stuart and Gaugler, 1996; Wang and Grewal, 2002).

UK211 and HF85 have both been commercialized in Europe and are amongst the most intensively studied strains of $H$. megidis. The differences between UK211 and HF85 in survival, lipid utilization, and size are stable: UK211 is consistently larger, survives longer, and uses its reserves more slowly than HF85 (present study; Fitters and Griffin, 2004; Fitters et al., 1997; Griffin et al., 1994; Hass et al., 2001), despite the fact that both of these isolates had been in culture for at least a decade by the time of these experiments.

There was a significant positive association between initial level of reserves and the rate at which they were depleted. This suggests that isolates with higher initial levels of reserves will survive longer, but interpretation is complicated by the high degree of intercorrelation among variables (Table 3). Initial reserves and area are highly correlated $\left(r^{2}=0.99\right)$. The positive association between $\mathrm{ET}_{50}$ and length was almost significant $(P=0.06)$, and such an association would be expected, as the respiration rate of most animals, including nematodes, decreases with increasing body size (Atkinson, 1980). In line with this expectation, species of Steinernema with larger IJs [S. feltiae (Filipjev) and $S$. glaseri (Steiner)] persisted longer in storage than $S$. carpocapsae and $S$. riobrave Cabanillas, Poinar and Raulston, which have smaller IJs (Patel et al., 1997).
Differences in motility were important in accounting for differences among isolates in the rate of depletion of energy reserves; head waves/minute accounted for $60 \%$ of the variation in $\mathrm{ET}_{50}$. Estimates vary for the contribution of locomotory activity to nematodes' energy budget relative to that of basal metabolism (see Atkinson, 1980; Wright, 1998). Experiments where IJs of plant and animal parasites were subjected to prolonged activation or inactivation indicate that for some species, locomotory activity may make a significant contribution to lipid depletion (Wright et al., 1989), especially where activity is intense (Croll, 1972). That locomotory activity contributed measurably to the depletion of reserves of $H$. megidis, is supported by the finding that there was a steep drop in reserves during the first week of storage (Fig. 2), and this corresponds to the period when IJs are highly active (Fitters and Griffin, 2004). With longer storage, reserves were depleted more slowly (Fig. 2), and an increasing proportion of IJs is inactive unless stimulated (Fitters and Griffin, 2004). However, as well as declining motility, age-related changes in metabolism (Croll and Mathews, 1973; Houthoofd et al., 2002) could also have contributed to the decline in rate of utilization of reserves by the IJs.

The variables used in this experiment explained only $88.5 \%$ of the variation in $\mathrm{ET}_{50}$ for $\mathrm{H}$. megidis. Other factors, which may have contributed but were not measured in these experiments, include variation in basal metabolic rate, the rate at which motility changes over time, or composition of reserves. First, basal metabolism is expected to contribute more than locomotory activity to respiration rate and depletion of reserves in absolute terms (Wright et al., 1999). The success of motility in explaining intraspecific variation in reserve depletion may indicate either that it makes a substantial contribution to their utilization (as discussed above), or that more active nematodes also tend to have higher basal metabolic rates. Assuming that locomotory activity does contribute to depletion of reserves, 
then intraspecific differences in the dynamic changes in activity may also contribute to differences in the $50 \%$ energy depletion time. Activity was measured only once, in freshly harvested IJs. This is when $H$. megidis IJs are at their most active (Dempsey and Griffin, 2002; Fitters and Griffin, 2004), and hence is the time when motility is expected to contribute most to the depletion of energy reserves. Activity of $H$. megidis IJs declines during storage in tap water, and the rate at which it changes differs among isolates (Fitters and Griffin, 2004). It should be noted that while some decline in activity levels of a population may be due to selective mortailty of more active individuals, this cannot account for the initial decline in activity of H. megadis over the initial weeks of storage at $20^{\circ} \mathrm{C}$, during which mortality is negligible (Dempsey and Griffin, 2002; Fitters and Griffin, 2004). Thirdly, isolates may differ in the composition of their reserves. Selvan et al. (1993a) suggested that the greater proportion of unsaturated fatty acids in Heterorhabditis compared to Steinernema spp. was a contributory factor to the poorer survival of Heterorhabditis spp., though this was not supported by Menti et al. (2003). Differences in the lipid composition of freshly harvested H. megidis EU17, UK211, and HF85 were not large (Fitters et al., 1999) and are unlikely to have contributed to the intraspecific differences in survival or rate of energy depletion rate seen here. However, the importance of glycogen and protein as energy sources has not been investigated for these isolates.

Not all IJs within the population use up their energy reserves at the same rate. When most IJs of UK211 and HF85 had reached $0.36 \mathrm{OD} \mathrm{U} / \mu \mathrm{m}^{2}$ or lower, some IJs were still quite dark $\left(0.46-0.48 \mathrm{OD} \mathrm{U} / \mu \mathrm{m}^{2}\right)$. Similar results have been reported for plant parasites (Storey, 1984; Van Gundy et al., 1967) and for Steinernema spp. (Patel et al., 1997). Variation in rates of lipid depletion within the population may be a general feature of IJs of nematode parasites. For EPN, this may be a population survival strategy of closely related propagules as suggested by Patel et al. (1997). If, instead, it reflects genetic diversity within isolates for energy conservation strategies, then the rare IJs that remain dark in storage may be a useful resource for strain improvement.

\section{Acknowledgments}

The research was part funded (Walsh fellowship) by Teagasc, the Irish Agriculture and Food Development Authority. We are grateful to Dr. Catherine Comiskey for her useful comments on the statistics of the manuscript.

\section{References}

Atkinson, H.J., 1980. Respiration in nematodes. In: Zuckerman, B.M. (Ed.), Nematodes as Biological Models, Vol. 2. Academic Press, New York, pp. 101-142.

Croll, N.A., 1972. Energy utilization of infective Ancylostoma tubaeforme larvae. Parasitology 64, 355-365.
Croll, N.A., Mathews, B.E., 1973. Activity, ageing and penetration of hookworm larvae. Parasitology 66, 279-289.

Dempsey, C.M., Griffin, C.T., 2002. Phased activity in Heterorhabditis megidis infective juveniles. Parasitology 124, 605-613.

Fitters, P.F.L., Griffin, C.T., 2004. Spontaneous and induced activity of Heterorhabditis megidis infective juveniles during storage. J. Nematol. 6, 911-917.

Fitters, P.F.L., Griffin, C.T, Dunne, R., 2001. Improved control of Otiorhynchus sulcatus at $9{ }^{\circ} \mathrm{C}$ by cold-stored Heterorhabditis megidis UK211. Biocont. Sci. Technol. 11, 483-492.

Fitters, P.F.L., Patel, M.N., Griffin, C.T., Wright, D.J., 1999. Fatty acid composition of Heterorhabditis sp. during storage. Comp. Biochem. Physiol. B 124, 81-88.

Fitters, P.F.L., Wright, D.J., Meijer, E.M.J., Griffin, C.T., 1997. Estimation of lipid reserves in unstained living and dead nematodes by image analysis. J. Nematol. 29, 160-167.

Gaugler, R., 2002. Entomopathogenic Nematology. CABI, Wallingford, UK.

Grewal, P., Ehlers, R.-U., Shapiro-Ilan, D., 2005. Nematodes as Biocontrol agents. CABI, Wallingford, UK.

Grewal, P., Georgis, R., 1998. Entomopathogenic nematodes. In: Hall, F.R, Menn, J.J (Eds.), Biopesticides: Use and Delivery. Human Press, Totowa, NJ, pp. 271-299.

Griffin, C.T., Finnegan, M.M., Downes, M.J., 1994. Environmental tolerances and the dispersal of Heterorhabditis: survival and infectivity of European Heterorhabditis following prolonged immersion in seawater. Fundam. Appl. Nematol. 17, 415-421.

Hass, B., Downes, M.J., Griffin, C.T., 2001. Correlation between survival in water and persistence in soil of ten Heterorhabditis spp. isolates. Nematology 3, 573-579.

Hominick, W.M., 2002. Biogeography. In: Gaugler, R. (Ed.), Entomopathogenic Nematology. CABI, Wallingford, UK, pp. 115-143.

Houthoofd, K., Braeckman, B.P., Lenaerts, I., Brys, K., de Vreese, A., Eygen, S.van, Fleteren, J.R.van, 2002. Ageing is reversed, and metabolism is reset to young levels in recovering dauer larvae of C-elegans. Exp. Gerontol. 37, 1015-1021.

Lewis, E.E., Selvan, S., Campbell, J.F., Gaugler, R., 1995. Changes in foraging behaviour during the infective stage of entomopathogenic nematodes. Parasitology 110, 583-590.

Long, S.J., Richardson, P.N., Fenlon, J.S., 2000. Influence of temperature on the infectivity of entomopathogenic nematodes (Steinernema and Heterorhabditis spp.) to larvae and pupae of the vine weevil Otiorhynchus sulcatus (Coleoptera: Curculionidae). Nematology 2, 309-317.

Menti, H., Patel, M.N., Wright, D.J., Perry, R.N., 2003. Lipid utilisation during storage of the entomopathogenic nematodes Steinernema feltiae and Heterorhabditis megidis from Greece and the UK. Nematology $5,31-37$.

Molyneux, A.S., 1985. Survival of infective juveniles of Heterorhabditis spp., and Steinernema spp. (Nematoda: Rhabditida) at various temperatures and their subsequent infectivity for insects. Rev. Nematol. $8,165-170$.

Patel, M.N., Wright, D.J., 1997. Glycogen: its importance in the infectivity of aged juveniles of Steinernema carpocapsae. Parasitology 114, 591-596.

Patel, M.N., Stolinski, M., Wright, D.J., 1997. Neutral lipids and the assessment of infectivity in entomopathogenic nematodes: observations on four Steinernema species. Parasitology 114, 489-496.

Qiu, L., Bedding, R., 1999. A rapid method for the estimation of mean dry weight and lipid content of the infective juveniles of entomopathogenic nematodes using image analysis. Nematology 1, 655-660.

Qiu, L., Bedding, R., 2000. Energy metabolism and its relation to survival and infectivity of infective juveniles of Steinernema carpocapsae under aerobic conditions. Nematology 2, 551-559.

Selvan, S., Gaugler, R., Grewal, P., 1993a. Water content and fatty acid composition of infective juveniles entomopathogenic nematodes during storage. J. Parasitol. 79, 510-516.

Selvan, S., Gaugler, R., Lewis, E.E., 1993b. Biochemical energy reserves of entomopathogenic nematodes. J. Parasitol. 79, 167-172. 
Stuart, R.J., Gaugler, R., 1996. Genetic adaptation and founder effect in laboratory populations of the entomopathogenic nematode Steinernema glaseri. Can. J. Zool. 74, 164-170.

Storey, R.M.J., 1984. The relationship between neutral lipid reserves and infectivity for hatched and dormant juveniles of Globodera spp. Ann. Appl. Biol. 104, 511-520.

Strauch, O., Niemann, I., Neumann, A., Schmidt, A.J., Peters, A., Ehlers, R.U., 2000. Storage and formulation of the entomopathogenic nematodes Heterorhabditis indica and H-bacteriophora. Biocontrol 45, 483-500.

Van Gundy, S.D., Bird, A.F., Wallace, H.R., 1967. Ageing and starvation in larvae of Meloidogyna javanica and Tylenchulus semipenetrans. Phytopathology 57, 559-571.

Wang, X.D., Grewal, P.S., 2002. Rapid genetic deterioration of environmental tolerance and reproductive potential of an entomopathogenic nematode during laboratory maintenance. Biol. Control 23, 71-78.

Woodring, J.L., Kaya, H.K., 1988. Steinernematid and heterorhabditid nematodes: a handbook of techniques. Fayetteville: Arkansas Agricul- tural Experimental Station, Southern Cooperative Series Bulletin 331. University of Arkansas Press.

Wright, D.J., 1998. Respiratory physiology, nitrogen excretion and osmotic and ionic regulation. In: Perry, R.N., Wright, D.J. (Eds.), The Physiology and Biochemistry of Free-living and Plant-parasitic Nematodes. CABI, Wallingford, UK, pp. 103-131.

Wright, D.J., Grewal, P.S., Stolinski, M., 1997. Relative importance of neutral lipids and glycogen as energy stores in dauer larvae of two entomopathogenic nematodes, Steinernema carpocapsae and Steinernema feltiae. Comp. Biochem. Physiol. 118B, 269-273.

Wright, D.J., Patel, M.N., Mason, J.M., 1999. Survival of entomopathogenic nematodes in relation to commercial application. In: Glazer, I., Richardson, P., Boemare, N., Coudert, F. (Eds.), Survival of Entomopathogenic Nematodes. European Commission, Brussels, pp. 43-54.

Wright, D.J., Roberts, I.T.J., Evans, S.G., 1989. Effect of the nematicide oxamyl on lipid utilization and infectivity in Globodera rostochiensis. Parasitology 98, 151-154. 